\section{(- OPEN ACCESS}

\title{
HIV testing behaviour and HIV prevalence among female sex workers in Ukraine: findings from an Integrated Bio-Behavioural Survey, 2013-2014
}

\author{
Anna Tokar, ${ }^{\oplus 1}$ lana Sazonova, ${ }^{2}$ Sharmistha Mishra, ${ }^{3,4}$ Pavlo Smyrnov, ${ }^{2}$ Tetiana Saliuk, ${ }^{2}$ \\ Jeffrey V Lazarus, ${ }^{1}$ Jacqueline E W Broerse, ${ }^{5}$ Maria Roura, ${ }^{1,6}$ James Blanchard, ${ }^{7}$ \\ Marissa L Becker ${ }^{7}$
}

\begin{abstract}
- Additional material is published online only. To view please visit the journal online (http://dx.doi.org/10.1136/ sextrans-2018-053684).

For numbered affiliations see end of article.
\end{abstract}

\section{Correspondence to} Anna Tokar, Barcelona Institute for Global Health (ISGlobal), University of Barcelona, c. Rosselló, 132, 2nd floor, ES-08036, Barcelona, Spain; annatokar@yandex.ru

Received 14 May 2018 Revised 3 December 2018 Accepted 16 December 2018 Published Online First 6 March 2019

\section{Check for updates}

(C) Author(s) (or their employer(s)) 2019. Re-use permitted under CC BY-NC. No commercial re-use. See rights and permissions. Published by BMJ.

To cite: Tokar $A$, Sazonova I, Mishra S, et al. Sex Transm Infect 2019:95:193-200.

\section{ABSTRACT}

Objectives Ukraine has one of the largest HIV epidemics in Europe, with high prevalence among female sex workers (FSWs). We aimed to identify factors associated with HIV testing and receipt of the test result in the last 12 months, HIV prevalence and self-reported positive status among FSWs in Ukraine.

Methods We used data from an Integrated BioBehavioural Survey among FSWs conducted in 20132014. The survey methodology combined three sampling strategies: time and location sampling, respondentdriven sampling and key informant recruitment. We used multivariable regression to identify factors associated with self-reported HIV testing in the last 12 months, HIV prevalence and self-reported positive status among FSWs living with HIV. Explored factors included: age, age at first sex, age at entry into sex work, education, marital status, employment status beside sex work, condom use with last paying or non-paying sexual partner, drug or alcohol consumption and sex work venue.

Results Recent HIV testing was low overall with only $63.2 \%$ of FSWs reported having tested and received their test result in the last 12 months prior to the survey. HIV prevalence was $7.1 \%$ overall, but only $45.0 \%$ of FSWs living with HIV were aware of their HIV status. Testing in the last 12 months with receipt of test result was less common among FSWs who used drugs ever in life (adjusted OR (AOR) 0.7, 95\% Cl 0.6 to 0.9), women soliciting clients indoors (AOR $0.8,95 \% \mathrm{Cl} 0.7$ to 0.9 ) and those not using a condom with last paying sexual partner (AOR 0.3, 95\% Cl 0.2 to 0.5 ). HIV positivity was associated with history of ever using drugs (AOR 2.3, $95 \% \mathrm{Cl} 1.4$ to 3.6 ) and soliciting clients outdoors (AOR $1.5,95 \% \mathrm{Cl} 1.1$ to 2.0 ). Women working indoors were less aware of their positive status (AOR $0.1,95 \% \mathrm{Cl} 0.1$ to 0.9 ).

Conclusion HIV prevalence is high among FSWs in Ukraine, and testing and knowledge of one's status remain insufficient. HIV testing programmes need to expand with strategies to reach specific subgroups of FSWs.

\section{INTRODUCTION}

Ukraine has one of the largest HIV epidemics in Europe with current estimates of HIV prevalence in the general population at $0.9 \%,{ }^{1}$ and higher rates among key affected populations including female sex workers (FSWs) and people who inject drugs. There is an estimated 80000 FSWs in Ukraine, ${ }^{2}$ of whom $7.0 \%$ are living with $\mathrm{HIV}^{3}$

Early diagnosis of HIV and sustained and effective immediate HIV treatment for SWs living with HIV could contribute to a more effective HIV response. ${ }^{4}$ In 2006, the Alliance for Public Health in Ukraine launched the first HIV testing intervention with rapid diagnostic tests across 12 pilot sites as a part of a comprehensive Harm reduction (HR) programme for key affected populations. The intervention was subsequently scaled up countrywide in 2007 and by 2014 was implemented in 25 oblasts (administrative regions). ${ }^{56}$

Despite a widespread testing programme, a large proportion of people are still unaware of their HIV status. ${ }^{78}$ At the beginning of 2017, a total of 127620 people living with HIV/AIDS (PLHV) were officially diagnosed and enrolled in care at the Ukrainian AIDS clinics, which constituted up to $54.0 \%$ of estimated population size of PLHV. ${ }^{1}$ There are no data on how many of those diagnosed and enrolled in care are FSWs, as this type of data is not collected in Ukraine.

To improve the design and implementation of HIV testing and care in Ukraine for FSWs, our aim was to identify factors associated with self-reported HIV testing and receiving test result in the last 12 months, HIV prevalence and knowledge of positive status among FSWs.

\section{METHODS}

\section{Study setting and population}

We performed secondary analysis of cross-sectional data collected within an Integrated Bio-Behavioural Survey (IBBS) among FSWs in Ukraine (IBBS, 20132014). Initial analysis was performed by Alliance for Public Health, Ukraine ${ }^{9}$; detailed description of the IBBS methodology is presented elsewhere. ${ }^{9} 10$ The study was developed and conducted by the international charitable foundation 'Alliance for Public Health' under support of the Global Fund to Fight AIDS, Tuberculosis and Malaria. Survey sites were selected to include geographically representative samples of FSWs; thus, data were collected in 25 capital cities of each oblast (administrative regions) of Ukraine. The field phase of the IBBS 
was completed during October to December 2013, followed by data validation, analysis and reporting during January to March 2014. In an effort to recruit diverse subpopulations of FSWs in terms of sociodemographic characteristics (age, marital status, education, income, and so on) and sex work venues (indoors, outdoors, via internet), the IBBS methodology combined three sampling strategies: time and location sampling (TLS), respondent-driven sampling (RDS) and key informant recruitment. For each particular survey site (city) the choice of sampling strategy was based on formative assessment, which was done among FSWs, brothel owners/managers, human rights activists, social workers and healthcare workers, who had sufficient experience and knowledge of the sex work scene in the city. For each study site, formative assessment included reviewing the geographical location of existing sex work venues of soliciting clients, their organisational structure and estimated size of population and socioeconomic background of women working there. Based on this assessment, the method for recruitment was selected.

\section{Study procedures}

Study staff (interviewers and healthcare workers) who had previous experience working with SWs were recruited and trained on the study methods and tools for the IBBS. FSWs were eligible to participate if they were women aged $\geq 14$ years who had exchanged sex for money/drugs/services or goods in the last 6 months; held Ukrainian citizenship; and provided written or verbal informed consent to participate. Participants completed an interviewer-administered questionnaire which collected information on sociodemographic characteristics, self-reported health status, use of public health services, sex work experience, alcohol, drug use and sexual behaviours, experiences of violence and HIV testing history. Finger-prick samples were collected by healthcare workers to perform HIV rapid diagnostic test using CITO TEST HIV 1/2/07, Abon Biotech/Hangzhou, PR China (prequalified by $\mathrm{WHO}^{11}$ ). HIV testing and pretest and posttest counselling were provided as per the National HIV Testing guidelines by the Ministry of Health of Ukraine. Individuals who tested positive were referred for confirmatory laboratory diagnostics and linkage to care at nearby government HIV clinics. Participants were able to decline testing and around $10 \%$ of eligible participants refused to participate in the study overall (90.4\% agreed). Participants received compensation of US $\$ 10$ for their time.

\section{Outcome variables}

We examined HIV testing in terms of three binary (Yes/No) outcome measures: (1) self-reported HIV testing and receipt of test result in the last 12 months (based on the Joint United Nations Programme on HIV/AIDS recommendations) ${ }^{7}$; (2) HIV prevalence; and (3) self-reported HIV positive status (knowledge of one's HIV status). HIV prevalence was determined by positivity based on rapid test at time of bio-behavioural survey. Self-reported HIV positive status was defined as those FSWs who were diagnosed HIV positive by rapid test and who had reported that they were living with HIV during the survey.

\section{Explanatory variables}

Although the choice of explanatory variables was limited by available data, we based our decisions on a systematic review our team conducted summarising evidence on predictors and barriers to HIV testing in FSWs. ${ }^{12}$ Based on these findings, we applied classification at the mesolevel and microlevel of the socioecological framework of acquisition of HIV. ${ }^{13}$ At a mesolevel we examined sex work venues. Sex work venues' most common method for soliciting clients was classified as outdoors ('on the street', 'on the highway' and 'at the stations') or indoors ('in the sauna', 'in the hotel' and 'at the night club, bar, restaurant, discothèque') or phone/internet. At a microlevel, variables included: age, age at first sex, age at start of sex work, education, marital status, employment beside sex work, condom use with last paying/non-paying sexual partner, ever in life drug use, injection drug use in the last 12 months and alcohol consumption in the last 30 days. We analysed variables of age at first sex and age at start of sex work as variables with 5 -year intervals per each category starting from the lowest presented value.

\section{Statistical analysis}

We calculated descriptive statistics, and excluded data as missing if responses were 'hard to answer' and 'refuse to answer'. Missing data were not included in the bivariate or multivariable analyses. Where data are missing, it is reported as missing in the tables. In bivariate analysis we compared categorical variables by $\chi^{2}$ test. We used multivariable logistic regression analysis to examine associations between explanatory variables and testing in the last 12 months, HIV prevalence and self-reported HIV positive status. We employed a backward stepwise technique using Wald $\chi^{2}$ test to select the final model of the best fit. Explanatory variables were removed one at a time if they were not associated with an outcome at $5 \%$ level of significance. We used SPSS (SPSS V.21) to conduct analyses. We presented both bivariate and multivariable results where associations were significant in the Results section; online supplementary annex files include all bivariate and multivariable results.

\section{RESULTS}

\section{Descriptive characteristics}

Sociodemographic characteristics are shown in table 1. Overall, the median age of participants was 28 years (IQR 19-37). The median age at first sex was 16 years (IQR 14-18) and the median age at first sex work was 20 years (IQR 14-26). Almost every second woman had 11 years of schooling. The majority of participants were unmarried and lived alone. Approximately $10 \%$ of participants had a permanent job other than SW and about half of participants were officially recognised by the state social support system as unemployed. Almost all women used a condom with last paying partner (96.8\%), while only about 1 in 5 reported condom use with non-paying partner $(18.8 \%)$. The majority had never used drugs (71.4\%), and $46.4 \%$ reported weekly alcohol use. About one-half of participants (53.0\%) solicited clients at multiple types of venues, overall the most common place of solicitation was either outdoor $(51.0 \%)$ or indoor venues $(52.8 \%)$. Internet/phone solicitation was less common (33.0\%).

\section{Self-reported testing and receipt of test result in the last 12 months}

In total, 63.2\% (95\% CI 61.8 to 64.5 ) of FSWs reported an HIV test in the last 12 months with receipt of test result (table 2). In the bivariate model, condomless sex with last paying sexual partner (OR $0.3,95 \%$ CI 0.2 to 0.5 ), any alcohol use in the last 30 days (OR $0.3,95 \%$ CI 0.2 to 0.5 ), previous experience of drug use (OR 0.7, $95 \%$ CI 0.6 to 0.8 ), soliciting clients indoors (OR $0.8,95 \%$ CI 0.7 to 0.9 ) and solicitation via phone/internet (OR $0.7,95 \%$ CI 0.6 to 0.8 ) were each associated with a lower likelihood of testing in the last 12 months. In the final multivariable model, the following variables were independently 


\begin{tabular}{|c|c|c|}
\hline Variables & $\mathrm{n}$ & $\%$ \\
\hline \multicolumn{3}{|l|}{ Age (years) } \\
\hline 14-18 & 132 & 2.7 \\
\hline $19-23$ & 1039 & 21.2 \\
\hline $24-28$ & 1497 & 30.5 \\
\hline $29-33$ & 1191 & 24.3 \\
\hline $34+$ & 1047 & 21.3 \\
\hline Median (IQR) & $28(20 ; 38)$ & \\
\hline \multicolumn{3}{|c|}{ Age at first sexual intercourse (years) } \\
\hline $6-13$ & 356 & 7.3 \\
\hline $14-18$ & 4252 & 86.7 \\
\hline $19-25$ & 259 & 5.3 \\
\hline Median (IQR) & $16(15 ; 19)$ & \\
\hline Missing & 40 & 0.8 \\
\hline \multicolumn{3}{|l|}{ Age at first sex work (years) } \\
\hline $12-13$ & 9 & 0.2 \\
\hline $14-18$ & 1242 & 25.3 \\
\hline $19-23$ & 2227 & 45.4 \\
\hline $24-28$ & 1067 & 21.7 \\
\hline $29-33$ & 252 & 5.1 \\
\hline $34+$ & 70 & 1.4 \\
\hline Median (IQR) & $20(14 ; 26)$ & \\
\hline Missing & 42 & 0.8 \\
\hline \multicolumn{3}{|l|}{ Education level } \\
\hline$<9$ years of schooling & 105 & 2.1 \\
\hline 9 years of schooling & 563 & 11.5 \\
\hline 11 years of secondary school & 2283 & 46.5 \\
\hline Vocational school & 1621 & 33.0 \\
\hline University degree & 334 & 6.8 \\
\hline \multicolumn{3}{|l|}{ Marital status } \\
\hline Married living with husband & 214 & 4.4 \\
\hline Married living with other SP & 137 & 2.8 \\
\hline Married living alone & 405 & 8.3 \\
\hline Unmarried living with SP & 922 & 18.8 \\
\hline Unmarried living alone & 3228 & 65.8 \\
\hline \multicolumn{3}{|c|}{ Employment status (besides sex work) } \\
\hline Schoolgirl/student & 351 & 7.2 \\
\hline Have casual earnings & 1414 & 28.8 \\
\hline Unemployed* & 1997 & 40.7 \\
\hline Housekeeper & 536 & 10.9 \\
\hline Incapacitatedt & 24 & 0.5 \\
\hline Have a permanent job & 565 & 11.5 \\
\hline Missing & 19 & 0.4 \\
\hline \multicolumn{3}{|c|}{ Condom use with last paying partner } \\
\hline No & 150 & 3.1 \\
\hline Yes & 4753 & 96.9 \\
\hline Missing & 3 & 0.1 \\
\hline \multicolumn{3}{|c|}{ Condom use with last non-paying partner } \\
\hline No & 967 & 19.7 \\
\hline Yes & 922 & 18.8 \\
\hline I had no such partner & 3018 & 61.5 \\
\hline \multicolumn{3}{|l|}{ Alcohol use in the last 30 days } \\
\hline Every day & 1171 & 23.9 \\
\hline More than once a week & 2274 & 46.4 \\
\hline Less than once a week & 1114 & 22.7 \\
\hline Never & 347 & 7.1 \\
\hline Drug use ever in life & & \\
\hline
\end{tabular}

Continued

\begin{tabular}{lrl}
\hline Table 1 Continued & & \\
\hline Variables & $\mathbf{n}$ & $\%$ \\
\hline Yes & 545 & 11.1 \\
\hline I used before, now I don't & 847 & 17.3 \\
\hline No, never used drugs & 3504 & 71.4 \\
\hline Missing & 10 & 0.2 \\
\hline $\begin{array}{l}\text { Injection drug use in the last 12 months } \\
\text { Yes }\end{array}$ & 292 & 6.0 \\
\hline No & 4614 & 94.0 \\
\hline Sex work venue: outdoors & & \\
$\quad$ No & 2402 & 49.0 \\
\hline Yes & 2504 & 51.0 \\
\hline Sex work venue: indoors & & \\
$\quad$ No & 2315 & 47.2 \\
\hline Yes & 2591 & 52.8 \\
\hline Sex work venue: phone/internet & & \\
\hline No & 3286 & 67.0 \\
\hline Yes & 1620 & 33.0 \\
\hline
\end{tabular}

*Unemployed by official records as sex work is not considered to be official occupation and cannot give official employment status (recognised by the government of Ukraine).

tIncapacitated - those who are receiving social security because of the limited employment due to disability.

FSWs, female sex workers; SP, sexual partner.

associated with a lower likelihood of testing and receipt of test result: condomless sex with last paying sexual partner (adjusted OR (AOR) $0.3,95 \%$ CI 0.2 to 0.5 ); any alcohol use in the last 30 days (AOR 0.3, 95\% CI 0.2 to 0.5); previous experience of drug use (AOR 0.7, 95\% CI 0.6 to 0.9 ); and soliciting clients indoors (AOR 0.8, 95\% CI 0.7 to 0.9 ) and via phone/internet (AOR 0.7, $95 \%$ CI 0.6 to 0.9 ).

\section{HIV prevalence}

Overall, $7.1 \%$ (95\% CI 6.4 to 7.8 ) of FSWs were HIV positive. In the bivariate model, HIV prevalence was higher among unmarried women who were living with a sexual partner (OR $2.0,95 \%$ CI 1.1 to 3.9); had casual earnings other than sex work (OR 2.8, 95\% CI 1.6 to 4.6); were unemployed (OR 2.5, 95\% CI 1.5 to 4.2 ), working as a housekeeper (OR $3.0,95 \%$ CI 1.7 to 5.2) or incapacitated (OR 13.9, 95\% CI 5.2 to 37.3); used drugs (OR 5.9, 95\% CI 4.4 to 7.9); and solicited clients outdoors (OR $2.6,95 \%$ CI 2.0 to 3.3 ).

In the final multivariable model (table 3 ), the following variables were independently associated with greater likelihood of HIV infection: being unmarried and living alone (AOR 2.7, 95\% CI 1.2 to 5.9 ) or being unmarried but living with sexual partner (AOR 2.6, 95\% CI 1.2 to 5.7); having a non-permanent job including casual earnings other than sex work (AOR 1.8, 95\% CI 1.0 to 3.1), being a housekeeper (AOR 2.3, 95\% CI 1.2 to 4.2 ), being unemployed (AOR 1.7, 95\% CI 1.0 to 2.9 ) or incapacitated (AOR 3.8, 95\% CI 1.2 to 11.8); used drugs ever in life (AOR 2.3, 95\% CI 1.4 to 3.7) or injected drugs in the last 12 months (AOR 2.9, 95\% CI 1.8 to 4.8 ); and soliciting clients outdoors (AOR 1.5, 95\% CI 1.1 to 2.0).

\section{Self-reported HIV status}

Only 45.0\% (95\% CI 39.7 to 50.0 ) of FSWs diagnosed with HIV reported they were HIV positive prior to testing in the survey. In the bivariate model, drug use ever in life (OR $8.3,95 \%$ CI 4.0 to 17.1 ) and injection drug use in the last 12 months (OR 4.7, 
Table 2 Bivariate and multivariable analysis of self-reported HIV testing and receipt of test result in the last 12 months among FSWs in Ukraine*

\begin{tabular}{|c|c|c|c|c|c|c|}
\hline \multirow{2}{*}{$\begin{array}{l}\text { Sociodemographic and behavioural } \\
\text { characteristics }\end{array}$} & \multicolumn{3}{|c|}{ Bivariate analysis } & \multicolumn{3}{|c|}{ Multivariable analysis } \\
\hline & n (\%) & OR $(95 \% \mathrm{Cl})$ & $P$ value & n (\%) & AOR $(95 \% \mathrm{Cl})$ & $P$ value \\
\hline \multicolumn{7}{|l|}{ Age (years) } \\
\hline $14-18$ & $66(1.6)$ & $1.4(0.7$ to 2.6$)$ & 0.24 & $66(1.7)$ & 1.4 (0.7 to 2.8$)$ & 0.29 \\
\hline $19-23$ & $790(19.3)$ & $1.5(1.2$ to 1.8$)$ & $<0.001$ & $783(19.7)$ & $1.4(1.0$ to 1.8$)$ & 0.02 \\
\hline $24-28$ & $1308(32.1)$ & 1.0 (0.8 to 1.3$)$ & 0.38 & $1288(32.5)$ & $1.0(0.7$ to 1.2$)$ & 0.90 \\
\hline $29-33$ & $1025(25.1)$ & $1.1(0.9$ to 1.4$)$ & 0.17 & $998(25.1)$ & $1.1(0.8$ to 1.4$)$ & 0.30 \\
\hline $34+$ & $888(21.8)$ & 1.0 (ref) & & $864(21.8)$ & 1.0 (ref) & \\
\hline $\mathrm{T}$ & 829 & & & 907 & & \\
\hline \multicolumn{7}{|l|}{ Condom use with paying SP } \\
\hline No & $100(2.5)$ & $0.3(0.2$ to 0.5$)$ & $<0.001$ & 3902 (97.5) & $0.3(0.2$ to 0.5$)$ & $<0.001$ \\
\hline Yes & $3974(97.5)$ & 1.0 (ref) & & $97(2.4)$ & 1.0 (ref) & \\
\hline Missing data & 832 & & & 907 & & \\
\hline \multicolumn{7}{|l|}{ Alcohol use in the last 30 days } \\
\hline Every day & $959(23.5)$ & $0.3(0.2$ to 0.5$)$ & $<0.001$ & $950(23.7)$ & $0.3(0.2$ to 0.5$)$ & $<0.001$ \\
\hline More than once a week & $1865(45.7)$ & $0.3(0.2$ to 0.4$)$ & $<0.001$ & $1823(46)$ & $0.3(0.2$ to 0.4$)$ & $<0.001$ \\
\hline Less than once a week & $952(23.4)$ & $0.4(0.2$ to 0.6$)$ & $<0.001$ & 939 (23.6) & $0.4(0.2$ to 0.6$)$ & $<0.001$ \\
\hline Never & $301(7.4)$ & 1.0 (ref) & & $287(7.2)$ & 1.0 (ref) & \\
\hline Missing data & 829 & & & 907 & & \\
\hline \multicolumn{7}{|l|}{ Drug use ever } \\
\hline Yes & $484(11.9)$ & $0.9(0.7$ to 1.1$)$ & 0.65 & $472(11.8)$ & $1.0(0.7$ to 1.3$)$ & 0.84 \\
\hline I used before, now I don't & $712(17.5)$ & 0.7 (0.6 to 0.8$)$ & $<0.001$ & $698(17.4)$ & 0.7 (0.6 to 0.9$)$ & 0.01 \\
\hline No, I never used drugs & $2874(70.6)$ & 1.0 (ref) & & $2829(70.7)$ & 1.0 (ref) & \\
\hline Missing data & 836 & & & 907 & & \\
\hline \multicolumn{7}{|l|}{ Sex work venue: outdoors } \\
\hline Yes & $2210(54.2)$ & $1.3(1.2$ to 1.5$)$ & $<0.001$ & $2154(53.8)$ & $1.4(1.1$ to 1.6$)$ & $<0.001$ \\
\hline No & $1867(45.8)$ & 1.0 (ref) & & $1845(46.2)$ & 1.0 (ref) & \\
\hline Missing data & 829 & & & 907 & & \\
\hline \multicolumn{7}{|l|}{ Sex work venue: indoors } \\
\hline Yes & $2047(50.3)$ & $0.8(0.7$ to 0.9$)$ & 0.01 & $2016(50.5)$ & $0.8(0.7$ to 0.9$)$ & 0.01 \\
\hline No & $2030(49.7)$ & 1.0 (ref) & & $1983(49.5)$ & 1.0 (ref) & \\
\hline Missing data & 829 & & & 907 & & \\
\hline \multicolumn{7}{|l|}{ Sex work venue: phone/internet } \\
\hline Yes & $1289(31.6)$ & 0.7 (0.6 to 0.8$)$ & $<0.001$ & $1267(31.6)$ & $0.7(0.6$ to 0.9$)$ & 0.01 \\
\hline No & $2788(68.4)$ & 1.0 (ref) & & $2732(68.4)$ & 1.0 (ref) & \\
\hline Missing data & 829 & & & 907 & & \\
\hline
\end{tabular}

$A O R$, adjusted $\mathrm{OR} ; \mathrm{Cl}$, confidence interval; FSWs, female sex workers; OD, odds ratio; SP, sexual partner.

95\% CI 2.2 to 9.9 ), as well as soliciting clients outdoors (OR $1.7,95 \%$ CI 1.0 to 3.0 ) predicted self-reported HIV positive status (table 4).

In the final multivariable model, women aged 29-33 years (AOR 54.8, 95\% CI 1.7 to 1709.7), who reported consuming alcohol in the last 30 days (AOR 5.9, 95\% CI 1.1 to 31.7) or ever using drugs (AOR 12.6, 95\% CI 2.3 to 68.0 ) and SWs soliciting clients via phone/internet (AOR 3.4, 95\% CI 1.4 to 8.4 ) were more likely to report their HIV positive status. SWs who solicited indoors were less likely to report their positive status (OR $0.3,95 \%$ CI 0.2 to 0.6 ).

\section{DISCUSSION}

To our knowledge, this is the first paper on factors associated with HIV testing behaviours, prevalence and self-reported HIV status among FSWs in Ukraine. Our study demonstrates that recent HIV testing remains low with only $63.2 \%$ of FSWs reported having tested and received their test results in the last 12 months. Further, only $45.0 \%$ of FSWs living with HIV were aware of their status.
Overall, FSWs who reported inconsistent condom use were less likely to test for HIV. As other studies have demonstrated, consistency of condom use might change with longer duration of relationships with sexual partners as FSWs might trust their partners more and perceive themselves to be at lower risk. ${ }^{14}{ }^{15} \mathrm{HIV}$ testing might be subsequently influenced by lower risk perceptions of women in longer relationships.

It is important to note that testing was lower among FSWs with previous experience of drug use and those soliciting clients indoors. HR programmes in Ukraine have now begun to prioritise the most vulnerable key populations, including people who currently use drugs and those working outdoors as an important population for testing. In other regions, such as Vietnam, Russia, Uzbekistan and Kenya, similar results of lower testing uptake among FSWs who use drugs have been shown, ${ }^{16-18}$ however, this is not consistent globally. ${ }^{19} 20$

Overall HIV prevalence in our study was 7.1\% among FSWs. This is lower than previous bio-behavioural surveys where prevalence was $10 \%$ among FSWs in $2011 .^{21}$ As previously shown in Ukraine, we found that women who reported injection drug 
Table 3 Bivariate analysis and multivariable analysis of HIV prevalence among FSWs in Ukraine

\begin{tabular}{|c|c|c|c|c|c|c|}
\hline \multirow{2}{*}{$\begin{array}{l}\text { Sociodemographic and behavioural } \\
\text { characteristics }\end{array}$} & \multicolumn{3}{|c|}{ Bivariate analysis } & \multicolumn{3}{|c|}{ Multivariable analysis } \\
\hline & n (\%) & OR $(95 \% \mathrm{Cl})$ & $P$ value & n (\%) & AOR $(95 \% \mathrm{Cl})$ & $P$ value \\
\hline \multicolumn{7}{|l|}{ Age (years) } \\
\hline $14-18$ & $133(2.7)$ & - & & $131(2.7)$ & - & \\
\hline $19-23$ & $1030(21.4)$ & $0.2(0.1$ to 0.3$)$ & $<0.001$ & $1022(21.6)$ & $0.2(0.1$ to 0.4$)$ & $<0.001$ \\
\hline $24-28$ & 1471 (30.6) & $0.4(0.3$ to 0.6$)$ & $<0.001$ & $1446(30.7)$ & $0.4(0.3$ to 0.6$)$ & $<0.001$ \\
\hline $29-33$ & $1148(23.8)$ & 0.7 (0.6 to 1.0$)$ & 0.10 & $1117(23.7)$ & 0.8 (0.6 to 1.1$)$ & 0.35 \\
\hline $34+$ & $1024(21.3)$ & 1.0 (ref) & & $999(21.2)$ & 1.0 (ref) & \\
\hline Missing data & 100 & & & 191 & & \\
\hline \multicolumn{7}{|l|}{ Education level } \\
\hline$<9$ years of schooling & $97(2)$ & $6.1(2.7$ to 13.4$)$ & $<0.001$ & $94(1.9)$ & 3.8 (1.5 to 9.2 ) & 0.01 \\
\hline 9 years of schooling & $554(11.5)$ & $2.5(1.3$ to 5.0$)$ & 0.01 & $540(11.4)$ & 2.3 (1.1 to 4.8$)$ & 0.02 \\
\hline 11 years of schooling & $2243(46.6)$ & 2.2 (1.2 to 4.2$)$ & 0.01 & 2199 (46.6) & 2.4 (1.2 to 4.7$)$ & 0.01 \\
\hline Vocational school & $1576(32.7)$ & 2.1 (1.1 to 4.1$)$ & 0.15 & $1551(32.9)$ & 2.0 (1.0 to 4.0$)$ & 0.04 \\
\hline University degree & $336(6.9)$ & 1.0 (ref) & & $331(7)$ & 1.0 (ref) & \\
\hline Missing data & 100 & & & 191 & & \\
\hline \multicolumn{7}{|l|}{ Marital status } \\
\hline Unmarried living alone & $3144(65.4)$ & $1.5(0.7$ to 2.8$)$ & 0.21 & $3090(65.5)$ & 2.7 (1.2 to 5.9$)$ & 0.01 \\
\hline Married living with other SP & $136(2.8)$ & $0.6(0.1$ to 2.0$)$ & 0.42 & $134(2.8)$ & 0.8 (0.2 to 2.8$)$ & 0.73 \\
\hline Married living alone & $400(8.3)$ & $1.6(0.7$ to 3.4$)$ & 0.18 & $396(8.4)$ & $2.0(0.8$ to 4.9$)$ & 0.09 \\
\hline Unmarried living with SP & $912(18.9)$ & $2.0(1.1$ to 3.9$)$ & 0.04 & $888(18.8)$ & $2.6(1.2$ to 5.7$)$ & 0.01 \\
\hline Married living with husband & $214(4.4)$ & 1.0 (ref) & & $207(4.4)$ & 1.0 (ref) & \\
\hline Missing data & 100 & & & 191 & & \\
\hline \multicolumn{7}{|l|}{ Employment status (besides sex work) } \\
\hline Schoolgirl/student & $350(7.3)$ & $0.1(0.0$ to 0.7$)$ & 0.02 & $347(7.4)$ & $0.3(0.0$ to 1.6$)$ & 0.19 \\
\hline Have casual earnings & $1380(28.8)$ & $2.8(1.6$ to 4.6$)$ & $<0.001$ & $1362(28.9)$ & $1.8(1.0$ to 3.1$)$ & 0.02 \\
\hline Unemployed ${ }^{*}$ & $1965(41)$ & $2.5(1.5$ to 4.2$)$ & $<0.001$ & $1926(40.8)$ & $1.7(1.0$ to 2.9$)$ & 0.03 \\
\hline Housekeeper & $522(10.9)$ & $3.0(1.7$ to 5.2$)$ & $<0.001$ & $516(10.9)$ & $2.3(1.2$ to 4.2$)$ & 0.01 \\
\hline Incapacitatedt & $23(0.4)$ & $13.9(5.2$ to 37.3$)$ & $<0.001$ & $22(0.5)$ & $3.8(1.2$ to 11.8$)$ & 0.02 \\
\hline Have a permanent job & $547(11.4)$ & 1.0 (ref) & & $542(11.5)$ & 1.0 (ref) & \\
\hline Missing data & 119 & & & 191 & & \\
\hline \multicolumn{7}{|l|}{ Condom use with non-paying SP } \\
\hline No & $949(19.7)$ & $0.7(0.5$ to 0.9$)$ & 0.04 & $932(19.7)$ & $0.5(0.4$ to 0.8$)$ & 0.01 \\
\hline I had no such partner & $2961(61.6)$ & $0.7(0.5$ to 0.9$)$ & 0.03 & $2910(61.7)$ & 0.7 (0.5 to 1.0$)$ & 0.08 \\
\hline Yes & $896(18.6)$ & 1.0 (ref) & & $873(18.5)$ & 1.0 (ref) & \\
\hline Missing data & 110 & & & 191 & & \\
\hline \multicolumn{7}{|l|}{ Drug use ever } \\
\hline Yes & $522(10.9)$ & $5.9(4.4$ to 7.9$)$ & $<0.001$ & $509(10.8)$ & $2.3(1.4$ to 3.7$)$ & $<0.001$ \\
\hline I used before, now I don't & $811(16.9)$ & 5.0 (3.8 to 6.5$)$ & $<0.001$ & $795(16.9)$ & $3.9(2.9$ to 5.2$)$ & $<0.001$ \\
\hline No & $3463(72.2)$ & 1.0 (ref) & & $3411(72.3)$ & 1.0 (ref) & \\
\hline Missing data & 100 & & & 191 & & \\
\hline \multicolumn{7}{|l|}{ Injecting drug use in the last 12 months } \\
\hline Yes & $280(5.8)$ & 6.2 (4.6 to 8.2$)$ & $<0.001$ & $270(5.7)$ & $2.9(1.8$ to 4.8$)$ & $<0.001$ \\
\hline No & $4526(94.2)$ & 1.0 (ref) & & $4445(94.3)$ & 1.0 (ref) & \\
\hline Missing data & 100 & & & 191 & & \\
\hline \multicolumn{7}{|l|}{ Sex work venue: outdoors } \\
\hline Yes & $2526(52.5)$ & $2.6(2.0$ to 3.3$)$ & $<0.001$ & $2458(52.1)$ & $1.5(1.1$ to 2.0$)$ & 0.01 \\
\hline No & $2280(47.4)$ & 1.0 (ref) & & $2257(47.9)$ & 1.0 (ref) & \\
\hline \multicolumn{7}{|l|}{ Missing data } \\
\hline \multicolumn{7}{|l|}{ Sex work venue: indoors } \\
\hline Yes & $2457(51.1)$ & 0.7 (0.6 to 0.9$)$ & 0.01 & $2418(51.2)$ & $0.9(0.7$ to 1.2$)$ & 0.99 \\
\hline No & $2349(48.8)$ & 1.0 (ref) & & $2297(48.7)$ & 1.0 (ref) & \\
\hline Missing data & 100 & & & 191 & & \\
\hline
\end{tabular}

*Unemployed by official records as sex work is not considered to be official occupation and cannot give official employment status (recognised by the government of Ukraine). tIncapacitated - those who are receiving social security because of the limited employment due to disability.

$\mathrm{AOR}$, adjusted $\mathrm{OR} ; \mathrm{Cl}$, confidence interval; FSWs, female sex workers; OR, odds ratio; SP, sexual partner. 
Table 4 Bivariate analysis and multivariable analysis of HIV self-reported status among FSWs in Ukraine*

\begin{tabular}{|c|c|c|c|c|c|c|}
\hline \multirow{2}{*}{$\begin{array}{l}\text { Sociodemographic and behavioural } \\
\text { characteristics }\end{array}$} & \multicolumn{3}{|c|}{ Bivariate analysis } & \multicolumn{3}{|c|}{ Multivariable analysis } \\
\hline & n (\%) & OR $(95 \% \mathrm{Cl})$ & $P$ value & n (\%) & AOR $(95 \% \mathrm{CI})$ & $P$ value \\
\hline \multicolumn{7}{|l|}{ Age (years) } \\
\hline $14-18$ & - & - & - & - & - & \\
\hline $19-23$ & $16(8.2)$ & $0.1(0.0$ to 0.5$)$ & $<0.001$ & $15(8)$ & $0.2(0.0$ to 1.2$)$ & 0.09 \\
\hline $24-28$ & $51(26.4)$ & $0.3(0.1$ to 0.6$)$ & 0.01 & $50(26.9)$ & $0.4(0.1$ to 1.4$)$ & 0.18 \\
\hline $29-33$ & $48(24.8)$ & $0.8(0.4$ to 1.6$)$ & 0.62 & $46(24.7)$ & $0.7(0.2$ to 2.0$)$ & 0.58 \\
\hline $34+$ & $78(40.4)$ & 1.0 (ref) & & $75(40.3)$ & 1.0 (ref) & \\
\hline Missing data & 157 & & & 164 & & \\
\hline \multicolumn{7}{|l|}{ Age at first sex work (years) } \\
\hline $12-13$ & $1(0.5)$ & - & - & $1(0.5)$ & - & - \\
\hline $14-18$ & $33(17.4)$ & $2.8(0.2$ to 28.6$)$ & 0.38 & $32(17.2)$ & $5.3(0.2$ to 135.0$)$ & 0.31 \\
\hline $19-23$ & $93(49.2)$ & $3.6(0.3$ to 36.5$)$ & 0.26 & $91(48.9)$ & $6.5(0.2$ to 155.3$)$ & 0.24 \\
\hline $24-28$ & $40(21.1)$ & $9.5(0.8$ to 101.0$)$ & 0.06 & $40(21.5)$ & 12.6 (0.5 to 320.6$)$ & 0.12 \\
\hline $29-33$ & $18(9.5)$ & 28.2 (1.9 to 417.3$)$ & 0.01 & $18(9.7)$ & 54.8 (1.7 to 1709.7$)$ & 0.02 \\
\hline $34+$ & $4(2.1)$ & 1.0 (ref) & & $4(2.1)$ & 1.0 (ref) & \\
\hline Missing data & 161 & & & 164 & & \\
\hline \multicolumn{7}{|l|}{ Alcohol use in the last 30 days } \\
\hline Every day & $64(33.1)$ & $1.8(0.6$ to 5.3$)$ & 0.27 & $63(33.8)$ & $5.9(1.1$ to 31.7$)$ & 0.03 \\
\hline More than once a week & $48(24.8)$ & $1.9(0.6$ to 6.1$)$ & 0.23 & $69(37.1)$ & $6.1(1.0$ to 38.2$)$ & 0.05 \\
\hline Less than once a week & $70(36.2)$ & $1.6(0.5$ to 4.7$)$ & 0.36 & $46(24.7)$ & 7.6 (1.2 to 45.1$)$ & 0.02 \\
\hline Never & $11(5.6)$ & 1.0 (ref) & & $8(4.3)$ & 1.0 (ref) & \\
\hline Missing data & 157 & & & 164 & & \\
\hline \multicolumn{7}{|l|}{ Drug use ever } \\
\hline Yes & $62(32.1)$ & 8.3 (4.0 to 17.1$)$ & $<0.001$ & $59(31.7)$ & $12.6(2.3$ to 68.0$)$ & 0.01 \\
\hline I used before, now I don't & $63(32.6)$ & $2.9(1.5$ to 5.3$)$ & $<0.001$ & $60(32.2)$ & $4.9(1.8$ to 12.9$)$ & $<0.001$ \\
\hline No, I never used drugs & $68(35.2)$ & 1.0 (ref) & & $67(36)$ & 1.0 (ref) & \\
\hline Missing data & 157 & & & 164 & & \\
\hline \multicolumn{7}{|l|}{ Injecting drug use in the last 12 months } \\
\hline Yes & $51(26.4)$ & $4.7(2.2$ to 9.9$)$ & $<0.001$ & $49(26.3)$ & $1.0(0.1$ to 6.0$)$ & 0.93 \\
\hline No & $142(73.5)$ & 1.0 (ref) & & $137(73.6)$ & 1.0 (ref) & \\
\hline Missing data & 157 & & & 164 & & \\
\hline \multicolumn{7}{|l|}{ Sex work venue: outdoors } \\
\hline Yes & $140(72.5)$ & $1.7(1.0$ to 3.0$)$ & 0.04 & $135(72.6)$ & $1.0(0.4$ to 2.6$)$ & 0.86 \\
\hline No & $53(27.4)$ & 1.0 (ref) & & $51(27.4)$ & 1.0 (ref) & \\
\hline Missing data & 157 & & & 164 & & \\
\hline \multicolumn{7}{|l|}{ Sex work venue: indoors } \\
\hline Yes & $82(42.4)$ & $0.3(0.2$ to 0.6$)$ & $<0.001$ & $79(42.5)$ & $0.4(0.1$ to 0.9$)$ & 0.02 \\
\hline No & $111(57.5)$ & 1.0 (ref) & & $107(57.5)$ & 1.0 (ref) & \\
\hline Missing data & 157 & & & 164 & & \\
\hline \multicolumn{7}{|l|}{ Sex work venue: phone/internet } \\
\hline Yes & $44(22.7)$ & $1.3(0.7$ to 2.3$)$ & 0.28 & $43(23.1)$ & $3.4(1.4$ to 8.4$)$ & 0.01 \\
\hline No & $149(77.2)$ & 1.0 (ref) & & $143(76.8)$ & 1.0 (ref) & \\
\hline Missing data & 157 & & & 164 & & \\
\hline
\end{tabular}

*Denominator-those FSWs who were diagnosed HIV positive with the rapid test.

AOR, adjusted odds ratio; $\mathrm{Cl}$, confidence interval ; FSWs, female sex workers; OR, odds ratio.

use and those working outdoors were more likely to be HIV positive. ${ }^{410}$ Our results support previous findings that HIV prevalence among FSWs in Ukraine may be driven by overlapping networks of SWs and people who use drugs. ${ }^{12}$

We identified a significant gap between self-reported positive HIV status and diagnosed HIV status with approximately half of FSWs living with HIV aware of their HIV status. This difference could be due to the high level of stigma associated with both HIV and sex work in the region, ${ }^{17} 22$ as stigma might prevent FSWs from testing and/or it may also affect their willingness to disclose a positive test result. Currently, prohibitive administrative (Statute $181 / 1)^{24}$ and criminal (Statutes 130, 302, 303) $)^{25}$ laws may fuel stigmatisation of SWs as well as lead to a violation of their human rights. Several recent public debates around the development of the first non-discriminative sex work policies in Ukraine were called off as they faced deep resistance from government and civil society to recognise sex work as a profession. As other research studies have demonstrated, prohibition of sex work can lead to stigma and discrimination, social exclusion, unsafe working condition, poor occupational health, low self-esteem and restriction on housing, travel and parenting. ${ }^{26-28}$ Thus, even though testing is available in Ukraine, stigma and criminalisation may constrain its accessibility and uptake, or may impact disclosure of positive HIV status, resulting in forced 
invisibility of FSWs and their needs. Moreover, women soliciting clients indoors were less likely to self-report positive HIV status, which might be due to fear that brothel owners/managers would know and would reject further employment. Our findings suggest that a range of implementation of outreach strategies with innovative delivery methods, including expanding HR programmes with a range of interventions such as needle/syringe exchange programme, condom delivery programmes, peer-topeer support, innovative testing approaches and strategies to reach those 'left behind' or missing is urgently required.

\section{Limitations}

Approximately $10 \%$ of eligible participants declined to participate and these individuals may be different from the women who chose to participate in our study. The cross-sectional study design does not allow us to determine casual relationships between outcomes and explanatory variables. As both RDS and TLS sampling strategies were concurrently applied across different IBBS rounds, the conclusions may not be generalisable to the entire population of FSWs in Ukraine. Sensitivity of the questions and stigma surrounding HIV and sex work may have resulted in informational bias. However, we argue that any informational bias may have been limited due to the engagement of trained study personnel who were experienced in working with FSWs. We were unable to verify self-reported HIV testing history and therefore, the proportion of previously tested may not be an accurate reflection because of the recall or self-reported bias. HIV positivity was determined by rapid test and not based on confirmatory serological assays. However, the rapid test used has a sensitivity and specificity over $99 \%{ }^{11}$ and has been used in other surveys and programmes in Ukraine. ${ }^{29}$ We also acknowledge limitation of the missing data which could reduce the statistical power of the study and can produce biased estimates. An additional limitation to this study is that these data were collected during 2013-2014 years, and thus might not fully reflect the current situation with HIV testing. However, we believe that our findings are still very relevant as HIV testing policies and HIV testing programmes among FSWs in Ukraine have been approved by the National HIV/AIDS Strategy for the period of 2013-2018 years, and thus HIV testing programmes and testing availability and uptake have likely not changed significantly during this time. Finally, our study did not address macrolevel factors (eg, HIV testing policies, healthcare funding, criminalisation of sex work or drug use) as we focused our analysis on bio-behavioural survey data. We acknowledge that these macrolevel factors are very important for contextualising the study findings and this is an important area for future research.

\section{Key messages}

- HIV prevalence is high among FSWs in Ukraine, yet HIV testing as well as knowledge of one's status remain insufficient.

- Women soliciting clients indoors were less likely to test for HIV and less likely to be aware of their positive status.

- FSWs who have used drugs were less likely to test and had higher HIV prevalence.

- FSWs who inject drugs should remain a priority for HIV prevention programs.

- HIV prevention programs need to expand testing strategies to ensure high levels of testing coverage to all sex workers regardless of place of solicitation.

\section{CONCLUSION}

HIV prevalence is high among FSWs in Ukraine; however, HIV testing as well as knowledge of one's status remains insufficient. Over half of FSWs living with HIV were unaware of their status. HIV prevention programmes in Ukraine need to expand with strategies to engage more difficult to reach subgroups of FSWs to ensure access, engagement and uptake of prevention services including testing and linkage to care for those FSWs living with HIV.

\section{Author affiliations}

'Barcelona Institute for Global Health (ISGlobal), University of Barcelona, Barcelona, Spain

${ }^{2}$ International Charitable Foundation 'Alliance for Public Health, Kiev, Ukraine ${ }^{3}$ Li Ka Shing Knowledge Institute, St Michael's Hospital, Toronto, Ontario, Canada ${ }^{4}$ Department of Medicine, University of Toronto, Toronto, Ontario, Canada

${ }^{5}$ Faculty of Science, Athena Institute, Vrije Universiteit Amsterdam and Amsterdam Public Health Institute, Amsterdam, The Netherlands

${ }^{6}$ Public and Patient Involvement Research Unit, Graduate Entry Medical School, University of Limerick, Limerick, Ireland

${ }^{7}$ Department of Community Health Sciences, Centre for Global Public Health, University of Manitoba, Winnipeg, Manitoba, Canada

\section{Handling editor Jane S Hocking}

Acknowledgements ISGlobal is a member of the CERCA Programme, Generalitat de Catalunya. We acknowledge the principal role of the IBBS in providing the data for secondary analysis for this study. We acknowledge the support of the International Charitable Foundation 'Alliance for Public Health', Kiev, Ukraine. We also acknowledge the field teams that implemented the IBBS and all the study participants.

Contributors AT conceived the study. AT and IS conducted the data analysis. AT wrote the paper. IS, SM and MLB contributed to writing the paper. JEWB, JB, JVL, IS, MLB, MR, PS, SM and TS provided critical comments on the manuscript. JEWB, JB, $J V L, I S, M L B, M R, P S, S M$ and TS approved the final version of the manuscript.

Funding This study was financed by the TransGlobal Health Program as a part of the Erasmus Mundus Joint Doctorate Programme. IBBS was funded by the Global Fund to Fight HIV/AIDS, Tuberculosis and Malaria.

Competing interests None declared.

\section{Patient consent for publication Not required.}

Ethics approval Ethical approval was obtained from the Research Ethics Boards of the Committee on Medical Ethics of the Gromachevsky Institute of Epidemiology and Infectious Diseases and from the Committee of the Professional Ethics of the Ukrainian Sociological Society (No 468, 04.04.2013).

Provenance and peer review Not commissioned; externally peer reviewed.

Open access This is an open access article distributed in accordance with the Creative Commons Attribution Non Commercial (CC BY-NC 4.0) license, which permits others to distribute, remix, adapt, build upon this work non-commercially, and license their derivative works on different terms, provided the original work is properly cited, appropriate credit is given, any changes made indicated, and the use is non-commercial. See: http://creativecommons.org/licenses/by-nc/4.0/.

\section{REFERENCES}

1 Ministry of Public Health of Ukraine. Informational bulletin "HIV infection in Ukraine "№ 47. Retrieved from the official web-site of the Ministry of Health of Ukraine. Kyiv, Ukraine: Ministry of Public Health of Ukraine, 2017.

2 International Charitable Foundation, "Intnernational for Public Health". Analytical report "Estimation of the size of key populations in Ukraine". Kyiv, Ukraine: International Charitable Foundation, "Intnernational for Public Health", 2017.

3 International Charitable Foundation "Intnernational for Public Health". Analitical report (National level) «behavioural monitoring and HIV infection prevalence among people providing sexual services for remuneration». Kyiv, Ukraine: International Charitable Foundation "Intnernational for Public Health", 2017.

4 Vitek CR, Čakalo J-I, Kruglov YV, et al. Slowing of the HIV epidemic in Ukraine: evidence from case reporting and key population surveys, 2005-2012. PLoS One 2014;9:e103657.

5 International Charitable Foundation "Intnernational for Public Health". Annual report. Kyiv,Ukraine: International Charitable Foundation "Intnernational for Public Health", 2006.

6 International Charitable Foundation "Intnernational for Public Health". Annual report Kyiv,Ukraine: International Charitable Foundation "Intnernational for Public Health", 2007. 
7 Joint United Nations Programme on HIVIAIDS (UNAIDS). 90-90-90 An ambitious treatment to help end the AIDS epidemic. Geneva, Switzerland: UNAIDS, 2014

8 Levi J, Raymond A, Pozniak A. Can the UNAIDS 90-90-90 target be reached? Analysis of national HIV treatment cascades, in IAS 20152015.

9 International Charitable Foundation "Intnernational for Public Health". Analitical report (National level) "Behavioural monitoring and hiv infection prevalence among people providing sexual services for remuneration». Kyiv,Ukraine: International Charitable Foundation "Intnernational for Public Health", 2015.

10 lakunchykova OP, Burlaka V. Correlates of HIV and inconsistent condom use among female sex workers in Ukraine. AIDS Behav 2016.

11 World Health Organization (WHO). 2016. Geneva, Switzerland. Available: https:// www.who.int/diagnostics_laboratory/procurement/170119_pqed_products_eligible_ for_procurement_2016.pdf?ua=1

12 Tokar A, Broerse JEW, Blanchard J, et al. HIV testing and counseling among female sex workers: a systematic literature review. AIDS Behav 2018;22:2435-57.

13 Blanchard JF, Aral SO. Emergent properties and structural patterns in sexually transmitted infection and HIV research. Sex Transm Infect 2010;86(Suppl 3):iii4-9.

14 Deering KN, Bhattacharjee P, Bradley J, et al. Condom use within non-commercial partnerships of female sex workers in southern India. BMC Public Health 2011;11(Suppl 6):S11.

15 Kerrigan D, Ellen JM, Moreno L, et al. Environmental-structural factors significantly associated with consistent condom use among female sex workers in the Dominican Republic. AIDS 2003;17:415-23.

16 Busza J, Castle S, Diarra A. Trafficking and health. BMJ 2004;328:1369-71.

17 Todd CS, Alibayeva G, Khakimov MM, et al. Prevalence and correlates of condom use and HIV testing among female sex workers in Tashkent, Uzbekistan: implications for HIV transmission. AIDS Behav 2007;11:435-42.
18 Tran BX, Nguyen LT, Nguyen NP, et al. HIV voluntary testing and perceived risk among female sex workers in the Mekong delta region of Vietnam. Glob Health Action 2013;6:20690.

19 Deering KN, Montaner JS, Chettiar J, et al. Successes and gaps in uptake of regular, voluntary HIV testing for hidden street- and off-street sex workers in Vancouver, Canada. AIDS Care 2015;27:499-506.

20 Shokoohi M, Karamouzian M, Khajekazemi R, et al. Correlates of HIV testing among female sex workers in Iran: findings of a national Bio-Behavioural surveillance survey. PLoS One 2016;11:e0147587.

21 International Charitable Foundation "Intnernational for Public Health". Analitical report (National level) "Behavioural monitoring and hiv infection prevalence among people providing sexual services for remuneration». Kyiv, Ukraine: International Charitable Foundation "Intnernational for Public Health", 2012.

22 DeHovitz J, Uuskula A, El-Bassel N. The HIV epidemic in Eastern Europe and Central Asia. Curr HIVIAIDS Rep 2014;11:168-76.

23 King EJ, Maman S, Bowling JM, et al. The influence of stigma and discrimination on female sex workers' access to HIV services in St. Petersburg, Russia. AIDS Behav 2013;17:2597-603.

24 The Parliament of Ukraine. (Verhovna Rada of Ukraine). Administrative codex of Ukraine, 2018. Available: http://zakon0.rada.gov.ua/laws/show/80731-10

25 The Parliament of Ukraine. (Verhovna Rada of Ukraine). Criminal codex of Ukraine, 2018. Available: http://zakon.rada.gov.ua/laws/show/2341-14/ed20120229

26 Harcourt C, Egger S, Donovan B. Sex work and the law. Sex Health 2005;2:121.

27 Gruskin S, Ferguson L. Government regulation of sex and sexuality: in their own words. Reprod Health Matters 2009;17:108-18.

28 Rekart ML. Sex-work harm reduction. The Lancet 2005;366:2123-34.

29 Smyrnov P, Williams LD, Korobchuk A, et al. Risk network Approaches to locating undiagnosed HIV cases in Odessa, Ukraine. J Int AIDS Soc 2018;21:e25040. 